\title{
Experimento didático: uma pesquisa para investigar mudanças cognitivas no processo de modelagem matemática
}

\author{
Marina Menna Barreto* \\ Vera Clotilde Garcia ${ }^{* *}$
}

Resumo: Este artigo relata uma pesquisa seguindo a metodologia do "experimento didático", ${ }_{1}^{1}$ desenvolvida com estudantes adolescentes, da $2^{\mathrm{a}}$ série do ensino médio, confrontados com um conjunto de atividades cujo centro é o processo de modelagem de um fenômeno ligado ao tema da sexualidade e às questões da gravidez precoce: a absorção e eliminação de um anticoncepcional oral. $\mathrm{O}$ objetivo foi tentar compreender as mudanças que ocorrem nos esquemas dos estudantes quando utilizam matemática conhecida para interpretar e resolver problemas reais. Concluímos que uma proposta didática que vincule o interesse pelo real com a matemática pode desenvolver mudanças cognitivas importantes, reorganizando esquemas insuficientes, atribuindo sentido à matemática e melhorando a percepção e a interpretação da realidade. O ensino usual não abre caminhos para a aplicação da matemática nas outras ciências, pois tem seus fundamentos em condições aparentemente absolutas e em concepções estáticas.

Palavras-chave: Ensino de matemática, Modelagem matemática, Experimento didático.

\footnotetext{
Mestre em Ensino de Matemática pela UFRGS. E-mail: marinambarreto@gmail.com * Professora do PPG-Ensino de Matemática da UFRGS. E-mail: veraclot@ufrgs.br 1 Deve ficar claro que, neste artigo, "experimento de ensino" refere-se a uma metodologia de pesquisa, bem definida e conceitualmente embasada na obra de Steffe \& Thompson (2000). Não se trata de uma experiência de ensino, no sentido usual da expressão.
} 


\begin{abstract}
This paper presents a research based on teaching experiment methodology. It involved medium level students confronting a set of activities focusing on the mathematical modeling of oral contraceptives assimilation and elimination phenomenon. The goal was to try to develop an understanding of the changes on students schema when applying mathematics to solve real problems. The research showed that the context of a pedagogical intervention model based on the representation of the living environment has potential to develop important cognitive changes, improving the reality perceptions and interpretation. The ordinary teaching does not open ways to mathematic application to other sciences because apparently it is founded over absolutely conditions and static conceptions.
\end{abstract}

Keywords: Mathematics teaching, Mathematical modeling, Teaching experiment.

\title{
Introdução
}

Tendências atuais da Educação Matemática no Brasil apontam para a importância de estabelecer relações entre a Matemática, outras disciplinas e outros contextos (LIMA,1999, 2005; MICOTTI, 1999; SCHOEN, 1995). Nesta perspectiva, a modelagem aparece como um caminho de integração e contextualização do ensino da Matemática (BARBOSA, 1999, 2001a, 2001b, 2002; BASSANEZI, 2004; BIEMBENGUTT; HEIN, 2003; PONTE, 1992; BRITO; ALMEIDA, 2005). Por outro lado, os Parâmetros Curriculares Nacionais (Brasil, 2002a, 2002b, 2002c, 2006) sugerem que temas transversais - saúde, meio ambiente, trabalho e consumo, educação sexual e pluralismo cultural - de interesse geral e urgente, no Brasil, permeiem e estejam presentes em todos os momentos do ensino (ALMEIDA, 2006; FIGUEIRÓ, 2000; TORRES, s.d,; TELOKEN; DEL PINO, 2006; TONNATO; SAPIRO, 2002) e, na Educação Matemática, encontramos 
trabalhos, embora poucos, nessa direção (CALDEIRA; MEYER, 2001; XAVIER, 2006; MORAES et. al., 2005). Resta perguntar: Uma proposta didática que vincule o interesse pelo real com a matemática pode desenvolver mudanças cognitivas? O que nós, professores pesquisadores, podemos aprender com nossos alunos, quando essa relação é feita?

Nessa perspectiva, relatamos uma pesquisa, adaptando a metodologia do experimento de ensino, seguindo as diretrizes de Steffe e Thompson (2000). A pesquisa foi desenvolvida com estudantes adolescentes, da $2^{\mathrm{a}}$ série do ensino médio, confrontados com um conjunto de atividades cujo centro é o processo de modelagem de um fenômeno ligado ao tema da sexualidade e às questões da gravidez precoce: a absorção e eliminação de um anticoncepcional oral. O objetivo do experimento foi tentar compreender as mudanças que ocorrem nos esquemas ${ }^{2}$ dos estudantes quando utilizam matemática conhecida para interpretar e resolver problemas reais.

O experimento didático focaliza três pontos: as interpretações e representações espontâneas dos estudantes a respeito do fenômeno; as representações matemáticas utilizadas para resolver problemas propostos na sequência de atividades conduzidas; o discurso matemático final que explica o fenômeno. $\mathrm{O}$ processo permitiu responder algumas questões: a) ao mobilizar a matemática conhecida para interpretar fenômenos reais, ocorrem processos de assimilação e acomodação que mudam os esquemas anteriores, criados para resolver problemas com o mesmos conteúdos matemáticos? b) a compreensão matemática possibilita a transformação das representações espontâneas sobre o real?

2 O esquema piagetiano é uma estrutura cognitiva dinâmica que se modifica ao longo do tempo, agregando conhecimento. A força motriz dessa modificação é dada pela relação dos processos coexistentes chamados por Piaget de assimilação e acomodação. Enquanto a assimilação age no sentido de adaptar o externo ao esquema, a acomodação age no sentido de adaptar o esquema ao externo. Cada esquema é composto por um contexto (que determina o conjunto de situaçóes nas quais ele pode ser aplicado), por um conjunto de sequências de ações (que representam sua aplicação) e por uma previsão (que indica o conjunto de estados finais no qual o esquema espera deixar o sistema após sua aplicação). (MUÑ̃Z, 1998, p.1) 


\section{Experimento de ensino: uma metodologia de pesquisa}

Para Steffe e Thompson (2000), o conhecimento dos estudantes aparece no que eles dizem e fazem durante uma atividade matemática, e uma meta básica dos pesquisadores num experimento é compreendê-lo. Para isso, é preciso investigar as modificaçóes que o aluno faz em suas maneiras de operar e, nessa direção, o experimento de ensino é uma ferramenta conceitual de pesquisa adequada: organiza investigações direcionadas para compreender o progresso do aluno num certo período, para explorar e para explicar sua atividade matemática.

Um experimento envolve uma sequência de episódios de ensino. No nosso caso, é um experimento reduzido, pois os objetivos foram modestos, embora interessantes: investigar os esquemas mobilizados pelos alunos para interpretar e representar o real e como eles podem mudar, como resultado da atividade matemática em um novo contexto.

As intenções gerais de uma pesquisa, nesta metodologia, são norteadas por hipóteses. Neste caso, delineamos as seguintes: a discussão do tema é interessante para os estudantes, capaz de desafiar sua imaginação matemática e gerar atividades matemáticas; as atividades matemáticas não estão muito distantes do conhecimento anterior do aluno, mas têm potencial para deixar emergir, sustentar e modificar os esquemas existentes; a proposta traz um novo contexto para a ação que exige a construção de novos esquemas, consequência da necessidade constante de adaptação e acomodação; a matemática desenvolvida esclarece e dá sentido ao real.

O experimento foi desenvolvido em três episódios: o real, a matemática do real, o real revisto com auxílio da matemática. Para cada um deles, o experimento permitiu: a) coletar e explorar as representações espontâneas dos alunos, frente a um vídeo; b) detectar os esquemas prévios mobilizados pelos estudantes na resolução das questões propostas e observadas mudanças que 
ocorrem, na medida do confronto com o real; c) verificar o desenvolvimento da compreensão do fenômeno na medida em que os estudantes o interpretam utilizando discursos matemáticos.

Num episódio, as ações e a linguagem dos alunos são fonte de perturbação e o foco das observaçôes é entender a originalidade do pensamento do outro, descrever sua coerência e provar sua fragilidade ou força em diferentes contextos. O raciocínio dos estudantes é o foco da atenção e, quando esse raciocínio prova ser rico, torna-se objeto de análise: a ação analítica segue a um insight nas operações mentais dos estudantes. Nas interações, é possível observar os momentos críticos quando reestruturações são indicadas por mudanças na linguagem e nas ações. A intenção do pesquisador não está na aprendizagem, mas na compreensão dos esquemas de assimilação dos estudantes como adaptam o externo a um certo modo de fazer e de pensar já sedimentado - e na maneira como esses esquemas podem mudar frente a novos desafios.

\section{Relato do experimento}

O experimento envolveu seis alunos de uma turma da $2^{a}$ série do Ensino Médio do Colégio de Aplicação da UFRGS, dois professores (pesquisadores autores deste artigo) e quatro estudantes do Curso de Licenciatura (observadores). Foi desenvolvido, durante quatro horas/aula, em uma sala de aula (Laboratório de Ensino) do Instituto de Matemática. Os alunos foram voluntários, selecionados através de um sorteio, com idades de quinze e dezesseis anos, três do sexo masculino e três do sexo feminino. O encontro foi parcialmente filmado e gravado, o material produzido pelos alunos foi coletado e analisado. Anotamos observações particulares, reflexões sobre as intervenções e sobre as interações, comentários e observações das outras pessoas envolvidas (alunos do Curso de Licenciatura), o que caracteriza a pesquisa como qualitativa. 


\section{Episódio 1: O vídeo e as representações iniciais}

O primeiro passo, no experimento, tinha como objetivo coletar e explorar as representações espontâneas dos alunos, frente a um vídeo (MENNA BARRETO, 2008) produzido para dar início às discussões sobre o uso de anticoncepcionais e para deixar emergir questões que desafiassem a imaginação matemática, com potencial para dar origem às atividades posteriores.

O vídeo consiste numa entrevista com uma médica ginecologista e focaliza sete diferentes tópicos relativos à prevenção da gravidez: diferentes métodos anticoncepcionais; o funcionamento da pílula anticoncepcional; diferentes tipos de pílula anticoncepcional; conselhos médicos relativos ao uso da pílula; orientação médica indicando a necessidade da consulta; lugares onde encontrar anticoncepcional gratuito; recomendaçôes sobre a adolescente e o uso da pílula.

O vídeo foi apresentado para o grupo, num aparelho DVD-TV da sala. Os alunos estavam dispostos em classes, em frente ao aparelho, os professores em pé, voltados para eles, e os licenciandos tratavam das filmagens, das observaçôes e das anotações. Os professores levantaram questôes para discussão: o uso continuado e diário de anticoncepcionais levaria a um acúmulo hormonal que poderia causar sequelas ao organismo feminino? O que ocorre quando se esquece de tomar uma ou mais pílulas? Qual a diferença da absorção de anticoncepcionais em forma de pílula, com uso diário ou da pílula do dia seguinte?

\section{Episódio 2: Atividades Matemáticas}

As atividades matemáticas estão no Anexo. Não estão muito distantes do conhecimento anterior do aluno e de seus esquemas já desenvolvidos para resolver situaçôes ligadas aos conteúdos das funções e gráficos. O objetivo da pesquisa, neste momento, foi analisar os esquemas anteriores dos alunos e as mudanças que ocorrem, à medida que são feitas vinculações com o real. 
A sequência didática foi baseada num modelo matemático do fenômeno da assimilação e eliminação de anticoncepcionais orais (ACO) (MENNA BARRETO, 2008) e propõe atividades que procuram criar um ambiente de modelagem. Envolve conceitos de variável, variáveis discretas e contínuas, conceito de função e construção de representações.

Os estudantes dispuseram-se em torno de uma grande mesa, juntamente com os professores e sendo assistidos pelos licenciandos. As atividades foram resolvidas numa situação aberta de interação e diálogo constante, em que todos se envolveram.

\section{Episódio 3: Discurso matemático}

O momento final foi planejado para deixar emergir as interpretações dos alunos sobre o fenômeno e suas respostas sobre as questões propostas, utilizando a linguagem e a matemática das atividades. Todos os alunos foram incentivados a explicar sua compreensão do fenômeno e a expor suas conclusões.

\section{Resultados do experimento}

O primeiro elemento extraído das nossas análises diz respeito à riqueza que o mundo real pode oferecer para o estudo da matemática, especialmente para o estudo das variáveis e de suas relações, das funções e das suas representações (tabular, gráfica, algébrica). Em particular, quando as aplicaçôes ocorrem num mundo que está próximo dos adolescentes e de seus interesses, é toda uma linguagem matemática que adquire sentido porque necessária para auxiliar na sua compreensão.

Perguntados, no início, sobre a evolução da quantidade de hormônio retido no corpo de uma mulher que toma anticoncepcionais diariamente durante, digamos dez anos, alguns mostraram com as mãos uma curva ascendente, crescendo sem limites e iniciando no zero. Perguntados sobre o que ocorreria se a mulher parasse de tomar, ou mesmo se esquecesse uma pílula, 
num certo dia, mostraram uma queda brusca, imediata para o nível zero. Estas imagens serviram para ilustrar o discurso matemático inicial, mostrando que havia uma representação intuitiva do fenômeno (errônea) e uma ausência de preocupação com a linguagem.

Destacamos o entusiasmo e a curiosidade, atitudes positivas para prosseguir com as atividades.

O segundo elemento diz respeito à análise do raciocínio dos alunos. A aprendizagem contextualizada, baseada em fenômenos reais, permite o desenvolvimento de procedimentos que diferem daqueles desenvolvidos no ensino usual. Na pesquisa, essas situações ocorreram quando os alunos tentaram traduzir para a linguagem matemática as informações verbais sobre o fenômeno real. Nesse momento os esquemas anteriormente construídos para tratar com funções e gráficos mostraram-se insuficientes.

Neste texto, vamos tratar de dois tópicos: o conceito de variável e sua relação com o gráfico da função; a identificação do modelo exponencial de decaimento.

Comecemos pela análise das situações com relação ao conceito de variável.

A primeira atividade solicitava a tradução para a linguagem gráfica matemática de um gráfico utilizado na Medicina (a representação da evolução da concentração de hormônios, no organismo de uma mulher que toma anticoncepcionais orais, durante o ciclo menstrual).

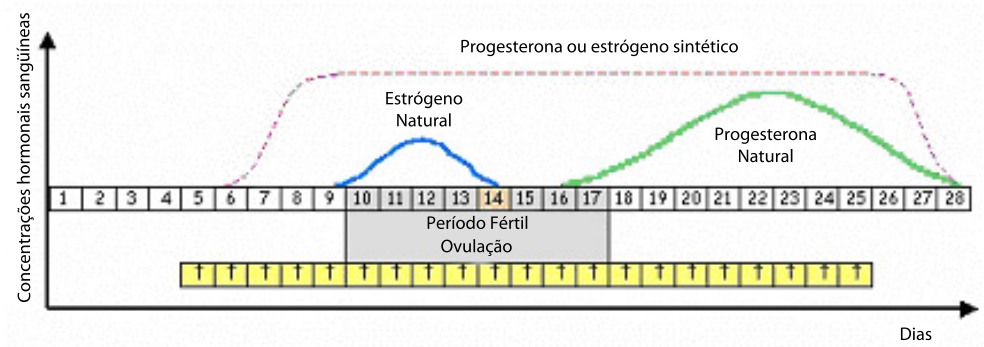

Figura adaptada de Thomas, J. A. \& Jones, J. E., 1979 
Cada seta da figura indica um dia de administração da pílula anticoncepcional, que inicia no quinto dia do ciclo.

Pedimos para o aluno determinar as variáveis utilizadas e para definir cada uma delas, indicando as unidades de medida. E colocamos outras questões: No eixo horizontal, o que significa o zero do gráfico? E o 1? E o 2? E o número 28?

Ao iniciarem a construção, surgiu a discussão sobre o significado do zero no eixo dos XX.

Aluno: O gráfico começa no zero ou no 1?

Professora : O que é o dia nove?

Aluno: É o dia 9 do ciclo menstrual.

Professora: E o zero é o quê?

Aluno: É o dia zero do ciclo menstrual.

Professora: Tem dia zero?

Aluno: Não. É a primeira hora do primeiro dia.

Professora: Esse número 1, significa o quê, no teu gráfico?

Aluno: É o primeiro dia.

Nesse momento, o que estava em jogo era a diferenciação entre a variável discreta (dia 1 , dia 2 , dia 3 ...) e a variável contínua (tempo em dias, sendo que o número 1 indica que transcorreu um dia e o número zero corresponde ao início do dia 1). Esse diálogo traz à tona um conflito: no esquema do aluno, para traçar gráficos, em geral, não é necessário pensar nas variáveis. O sistema de eixos sempre se apresenta com o zero na origem e este é absoluto, não questionável.

Prossegue a análise na questão 2 .

2) Uma pessoa tomou um comprimido de anticoncepcional às 20h. Sabemos que a concentração da droga no sangue decai com o tempo, reduzindo-se à metade a cada doze horas. Elabore um gráfico para expressar o decaimento dessa concentração, num período de um dia. E num período de três dias? Encontre uma expressão matemática para criar um modelo para o fenômeno da absorção de uma única pílula anticoncepcional.

Focalizamos uma resposta interessante (observe a primeira curva, que mostra o decaimento exponencial de um único comprimido): 


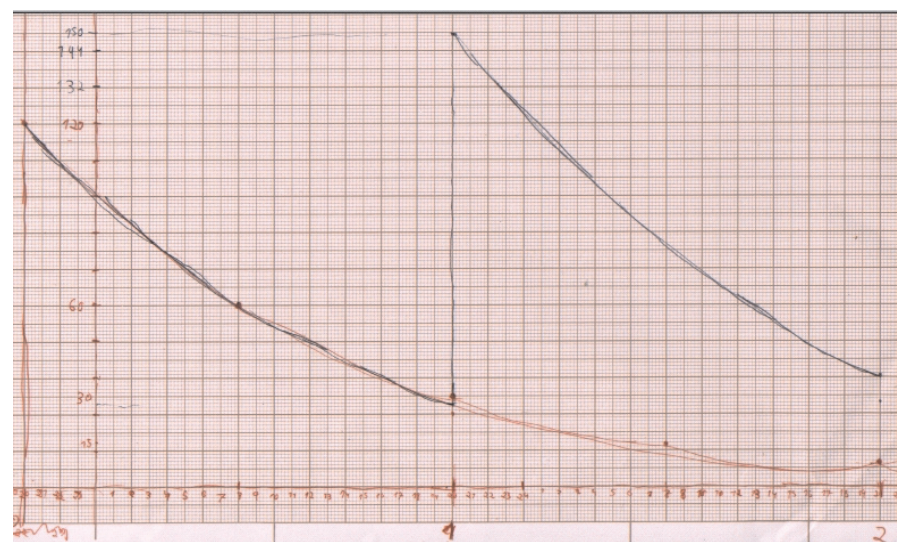

Gráfico 1

$\mathrm{O}$ aluno marcou, na origem do eixo dos XX, a hora zero do dia em que a pessoa tomou a primeira pílula. Como ela ingeriu o comprimido às 20 horas, o gráfico inicia no segundo quadrante. $\mathrm{O}$ número 20 foi localizado no eixo XX negativo e o eixo foi segmentado em partes correspondentes a 24 horas. Num certo momento, o aluno questiona o que está fazendo e os números são riscados. $\mathrm{O}$ esquema antigo é posto em dúvida. Vejamos outro aluno:

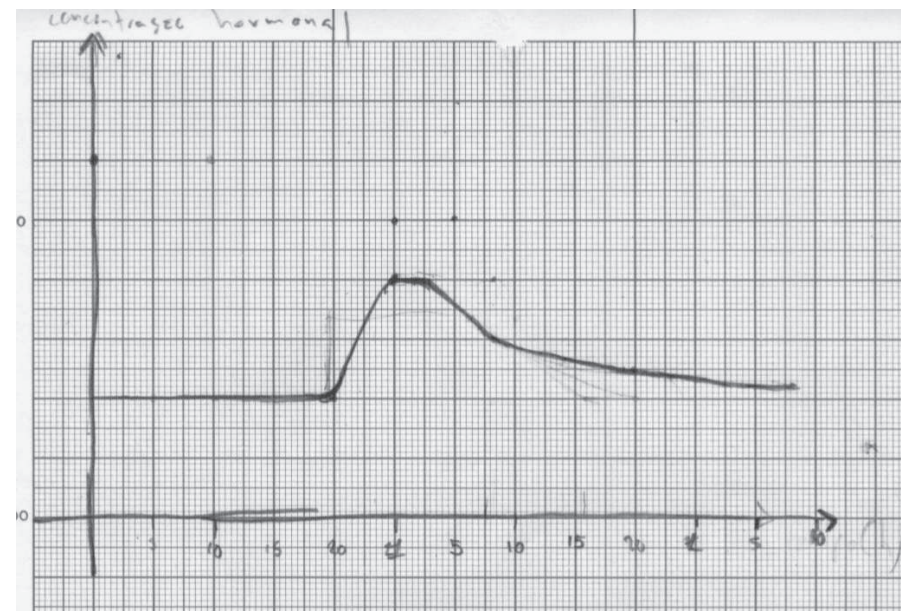

Gráfico 2 
Ao construir o gráfico, o aluno repete no eixo dos XX intervalos de 0 a 24 horas (faz uma aproximação, marcando 25 , pois escolheu a escala 1:5). Para ele, zero hora deve estar na origem dos eixos, e, como o dia tem 24 horas, a repetição dos dias é representada por intervalos de 24 horas. Antes das 20 horas, a quantidade de hormônio é constante, só ali é ingerido o ACO.

Constatamos, em diferentes soluçôes, a mesma dificuldade, que evidencia um esquema no qual não é usual pensar no significado das variáveis.

Em geral, na construção de gráficos, na escola, o aluno recebe funções dadas na forma algébrica e é solicitado a traçar seus gráficos. Esse traçado inicia-se com dois eixos ortogonais padronizados, que são numerados com os números inteiros ou alguma variação com múltiplos de 5 , de 10 ou de $\pi / 2$, no caso das funções trigonométricas. Em qualquer caso, é absolutamente claro para eles que o número zero ocupa o ponto de origem do sistema, onde ambos os eixos se cruzam e não há questionamento sobre o significado do zero, do 1 ou do 2.

No nosso caso, o gráfico não é decorrente de uma expressão algébrica, é uma representação de um fenômeno real. Como tal, compreendendo o fenômeno, ele se torna claro, tanto que as curvas são traçadas e as explicações verbais são corretas, mas o processo inicia quando o primeiro comprimido é ingerido, às 20 horas, o que causa conflito.

O primeiro passo para as representações matemáticas, neste tipo de problema, é definir as variáveis. Quem são as variáveis desse fenômeno e em que conjunto elas variam? Sem essas respostas, não há como numerar os eixos.

O que falta, no esquema de raciocínio dos alunos, é perceber que essa definição é necessária. É preciso definir a variável independente, o tempo, e definir o que significa o tempo ser igual a zero. Parece suficiente para eles (e para muitos de nós professores) afirmar que o gráfico relaciona quantidade de hormônios e tempo, quantidade x tempo. Mas de que tempo estamos falando? Tempo decorrido a partir do momento em que o fenômeno inicia, isto é, decorrido desde a ingestão do primeiro comprimido. 
Isso significa que o zero do sistema é relativo: $\mathrm{t}=0$ corresponde ao momento do dia (20h) no qual a primeira pílula é ingerida.

Essas situações mostram que a compreensão do fenômeno, obtida a partir do vídeo e das discussões, ocasionou modificação nos esquemas. Tentando adaptar o externo a um modo de agir usual, surgiram conflitos e questionamentos sobre o significado das variáveis, dos eixos e dos números que ali estão.

Entendemos que a compreensão do conceito de variável é essencial para trabalhar com aplicações da matemática e para dar início a qualquer processo de modelagem matemática. É preciso definir as variáveis para poder transitar entre as múltiplas representações das funçôes e para desenvolver a habilidade de relacionar o conceito de função com outras áreas e outros contextos.

Seguimos as diretrizes de Demana e Leitzel (1995, p. 74), que defendem a ideia de que uma situação, um problema ou um fenômeno deve ser descrito, a princípio verbalmente, sem nenhuma linguagem formal, mas, já neste momento, é preciso destacar as variáveis envolvidas:

(...) a introdução de variáveis para representar relaçôes funcionais em situações problemas concretas dá aos alunos a percepção de que as variáveis podem representar números de vastos conjuntos numéricos e que são instrumentos úteis na descrição de generalizações.

Partimos para a análise da questão do reconbecimento da função exponencial.

Diálogo a respeito do gráfico 1 :

Aluno 1: Primeiro eu marquei o primeiro ponto às 20 horas, daí depois eu peguei 12 horas depois e marquei a metade dos 120, que daí, seria 60 . Daí, marquei mais 12 horas e fiz a metade de 60, deu 30. Depois mais 12 horas, fiz a metade de 30 , que é 15 , e fui indo assim, marcando os pontos. E daí, como a variação ficava meio assim (mostrou com as mãos uma curva), então o gráfico é exponencial.

Professora: Tu achas que é um gráfico exponencial? Por quê?

Aluno 1: Porque se eu fizesse um ponto entre estes dois (indicou dois pontos consecutivos, sinalizando em relação ao eixo dos $\mathrm{x}$ ) daria um pouco mais abaixo (mostrando no gráfico onde seria o ponto) e não no meio. 
Observamos que o aluno identifica o modelo exponencial de decaimento (a função) sem associá-la à descrição verbal. Descreveu o comportamento do fenômeno mas não percebeu que dividir por 2 sucessivamente significa multiplicações sucessivas por $1 / 2$, o que demonstra o padrão construtivo da progressão geométrica, podendo ser origem da função exponencial. $\mathrm{O}$ reconhecimento da função exponencial se deu conforme um esquema pré-elaborado de comparar o gráfico novo com um modelo padrão, um protótipo. Ele identifica a curva exponencial pela sua forma: uma forma conhecida. Aparentemente, para ele, a curva representa uma função exponencial, porque não é reta.

Nessa mesma perspectiva, podemos analisar a fala de outro aluno, observando uma tabela de valores para tempo e quantidade, recém-construída:

Aluno 2: "Eu sei que vai dar uma exponencial decrescente, mas a fórmula que eu conbeço é $y=a^{-x}$ e a minha colega diz que a resposta aqui é $y=(1 / 4)^{x}$. Não estou entendendo".

Esta situação sugere que o esquema construído previamente leva-o a enfrentar esta questão - buscar a expressão matemática da função apresentada graficamente - a partir da comparação com expressões prototípicas, padronizadas, sem muita variação nas representações.

Nessa direção, Tall e Bakar (1992) trazem resultados de pesquisas que demonstram ser usual que os estudantes desenvolvam "exemplos prototípicos" para conceitos abstratos, tais como o conceito de função. Ao investigar um gráfico, eles recorrem aos seus protótipos mentais. Se há ressonância a resposta é correta, se não há ressonância o sujeito se sente confuso, procurando em sua mente por um significado para a questão, tentando encontrar uma razão pela falha em encontrar uma imagem mental. É o que ocorre com o aluno 2, que demonstra conflito entre os elementos que compóem a imagem conceitual que ele produziu para a função exponencial: a fórmula prototípica não coincide com aquela que emerge do modelo. 
Carlson, Oehrtman e Thompson (2007) trazem resultados que também contribuem para nossa análise. Pesquisas mostram que muitos estudantes reconhecem uma função linear ou quadrática pela forma: toda curva com forma de U é uma parábola, por exemplo. Isso não surpreende, quando se percebe que as funções são tratadas, na escola, a partir de tipos específicos, relacionadas com suas fórmulas e com a forma de seus gráficos. Na escola, em geral, os estudantes pensam no gráfico de uma função como sendo uma curva (um objeto fixo) no plano, retrato de uma equação. Esses autores colaboram com sugestões para o ensino, propondo que seja privilegiado, na sala de aula, o raciocínio covariacional, que significa coordenar uma imagem de duas quantidades variando e atentar sobre a maneira como uma delas muda com relação à outra. Essa seria uma visão de função como um processo, demonstrada quando os alunos traçam gráficos no ar, sem grande preocupação com valores numéricos.

Podemos perceber que a proposta que vincula conhecimentos de função com a necessidade de compreender e descrever um fenômeno real faz emergir esquemas prévios, causa conflitos, exige mudanças.

Verificamos aqui as indicações de Ponte (1990). Para que o aluno seja capaz de construir tabelas, calcular valores numéricos e desenvolver um sentido quantitativo ele deve ter a oportunidade de trabalhar com números concretos e, se possível, provenientes de diferentes contextos da vida real. Só assim poderão compreender melhor o significado das funçôes.

$\mathrm{O}$ terceiro elemento significativo que emergiu da pesquisa foi o desenvolvimento da percepção dos estudantes a respeito do fenômeno e o desenvolvimento do vocabulário matemático utilizado para explicá-lo. No começo do estudo, os estudantes forneceram representações e interpretações intuitivas e errôneas. 
Ao final, o fenômeno foi representado matematicamente e explicado verbalmente com termos não utilizados nas nossas atividades, mas trazidos dos esquemas e conhecimentos anteriores, mostrando um processo de assimilação e adaptação, favorecido pelo novo contexto.

A análise do seguinte diálogo corresponde ao desejado no episódio 3, momento final planejado para deixar emergir as interpretações dos alunos sobre o fenômeno, utilizando a linguagem matemática.

Sobre a questão seguinte:

Uma pessoa tomou um comprimido de anticoncepcional às $20 \mathrm{~h}$. A bula do remédio informa que a quantidade de hormônio presente em cada pílula é de 120 microgramas (O que é isso?) e que essa quantidade decai com o tempo, reduzindo-se à metade a cada 12 horas. As $20 \mathrm{~h}$ do dia seguinte, ela toma um novo comprimido. Elabore um gráfico para expressar a variação dessa concentração, num período de dois dias.

Professora: Se toma uma pílula só, a quantidade cai. E se toma todos os dias?

Aluno: Então sobe e cai, sobe e cai (faz gestos, oscilando a mão).

Professora: A concentração de droga pode ir para 500? Para 1000?

Aluno: Não vai, porque vai crescendo cada vez menos. Após muito tempo, quase não cresce mais (mostra um gráfico semelhante ao Gráfico 3 , a seguir) tem uma assíntota aqui em cima: um limite que não vai ser ultrapassado.

Esse diálogo mostra que o aluno consegue utilizar um discurso matemático para explicar o fenômeno, utilizando termos como "assíntota" e "limite", num sentido adequado e coerente. O gráfico que ele imagina (sem considerarmos a dificuldade da numeração do eixo dos XX) é muito semelhante ao gráfico que representa o modelo científico para absorção e eliminação de drogas no organismo (Gráfico 3). 


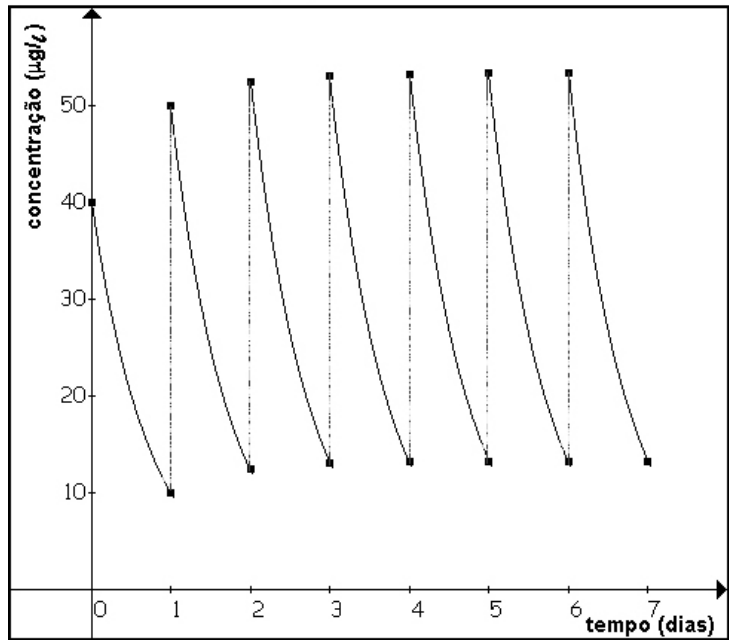

Gráfico 3

É preciso destacar que os esquemas anteriores, desses alunos, eram bem articulados e eficientes para resolver as questóes e problemas colocados pela escola (e pelo vestibular). Os alunos do Colégio de Aplicação convivem num ambiente privilegiado de ensino e demonstraram conhecimento de funçôes e habilidades para construir gráficos, acima da média, se comparamos com outros adolescentes, de outras escolas, que também foram desafiados com essas atividades. ${ }^{3}$ Contudo, foram colocados em confronto com uma situação-problema real e nova, nunca antes pensada que exigia um processo de modelagem completo: desde a compreensão da situação verbal e definição das variáveis até a construção de modelos gráfico e algébrico. Nesse confronto, surgiram conflitos. As novas exigências mostraram fragilidades nos esquemas anteriores que ainda não haviam aparecido

3 Uma sequência de ensino mais ampla foi testada na Escola Estadual Odila Gay da Fonseca, duas turmas da $1^{a}$ série do Ensino Médio (50 alunos), durante 16 horasaula e 18 horas-aula para cada turma. Foi realizada, no período de 17 de abril a 21 de maio de 2007, durante o turno da tarde, em três dias da semana. Veja mais em Menna Barreto (2008). 
e forçaram mudanças, com assimilação e acomodação de novas formas de agir e raciocinar.

\section{Considerações finais}

Nossas hipóteses foram validadas no experimento. A discussão do tema mostrou-se interessante para os estudantes, capaz de desafiar sua imaginação matemática e gerar atividades matemáticas. Estas, por sua vez, estavam próximas do conhecimento anterior do aluno, o que foi percebido na sua disposição e prontidão para iniciar as tarefas. Nesse processo, emergiram esquemas anteriores, mostrando fragilidades e favorecendo mudanças. A proposta trouxe um novo contexto para ação que exigiu a construção de novos esquemas (consequência da necessidade constante de adaptação do real ao esquema e do esquema ao real). Ao final, a matemática desenvolvida esclareceu e deu sentido ao real.

Finalmente, nossas perguntas iniciais podem ser respondidas. Observamos e demonstramos que uma proposta didática que vincule o interesse pelo real com a matemática pode desenvolver mudanças cognitivas, reorganizando esquemas insuficientes, atribuindo sentido à matemática e melhorando a percepção e interpretação da realidade. Podemos aprender com nossos alunos, quando essa relação é feita, observando, destacando e analisando de perto suas dificuldades e a necessidade de se adaptar a um novo contexto. Parece-nos que o ensino usual não abre caminhos para a modelagem de fenômenos reais fora dos contextos mais utilizados (Física, por exemplo). Os fundamentos do ensino incluem condiçôes que parecem dadas e absolutas, mas que são relativas no mundo real; além disso, a forma de trabalhar as funções elementares, em particular a função exponencial, não permite perceber as características construtivas que são consideradas, num trabalho de modelagem.

O resultado do nosso estudo leva a crer no potencial do ensino da Matemática nos contextos reais, principalmente aqueles 
que são interessantes e desafiadores para a imaginação matemática do aluno.

Este é um trabalho de pesquisa, realizado em condições ideais, no interior da Universidade, com alunos voluntários, curiosos e dispostos a aprender, oriundos de um Colégio de Aplicação. Neste contexto, cumprimos nossos objetivos, validamos nossas hipóteses e respondemos às questões investigativas, tratando de divulgar os resultados obtidos. Porém, como toda pesquisa na área da Educação Matemática, da Educação, e, num âmbito mais geral, das ciências humanas, esses resultados não podem ser generalizados. Não podemos esperar sucesso e resultados similares nas condições de trabalho usuais de um professor, com 30 ou mais alunos (que não estão ali voluntariamente e tampouco se apresentaram com interesse e motivação prévios), que deve obedecer as normas de sua instituição, que tem horários, avaliações e programas a cumprir.

Posto isso e, apesar disso, acreditamos nas possibilidades de aplicação desta sequência de atividades. Como já foi dito, o material traz em si um bom potencial para desencadear curiosidade, discussões e interações (condições básicas para que qualquer aprendizagem ocorra); e pode propiciar mudanças positivas nas concepções do aluno, sobre matemática (de corpo de conhecimento estático para um modo de compreender o mundo) e sobre o conceito de função, das funções elementares e de suas representações (modelos para fenômenos dinâmicos). Mais do que isso, pode mudar as concepçóes do próprio professor a respeito da matemática, do ensino, do planejamento e da organização da sua sala de aula. Fica aqui o desafio. Por que não experimentar?

\section{Anexo}

Atividade 1: Os gráficos a seguir foram elaborados na área médica. O primeiro indica a relação entre o nível hormonal da mulher que não toma anticoncepcional e o seu ciclo menstrual. 


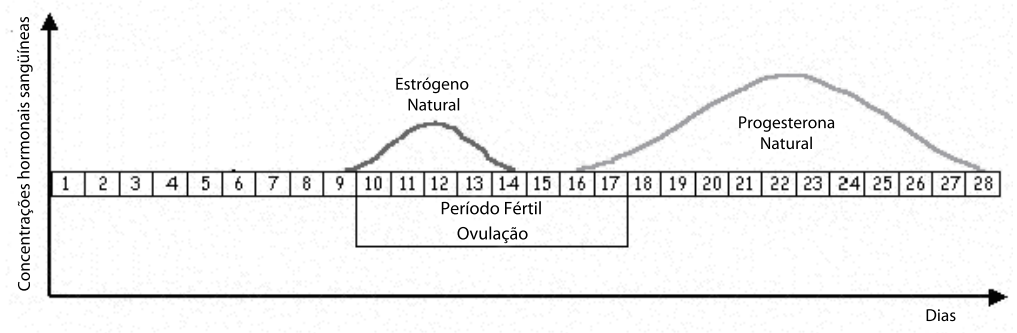

Gráfico extraído e adaptado de livro de farmacologia (THOMAS; JONES, 1979), mostrando o comportamento da concentração de estrógeno e progesterona em um ciclo menstrual normal de 28 dias.

Com o uso diário de anticoncepcional, o gráfico se transforma, e, no lugar dos picos de estrogênio e progesterona, temos um nível estável de tais hormônios, de maneira que a ovulação fica impedida de acontecer.

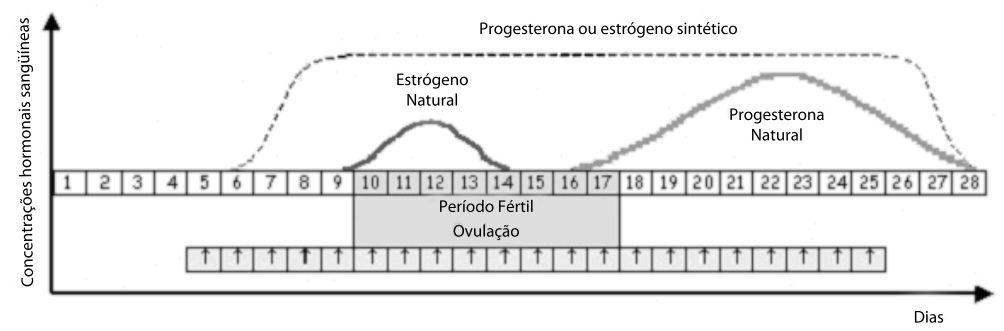

Este gráfico ilustra o mesmo comportamento da concentração hormonal da Figura 7.1 comparando-o com a concentração hormonal de quando se faz uso do anticoncepcional oral. As setas indicam a ingestão diária de ACO, que inicia no quinto dia do ciclo e tem duração de 21 dias (THOMAS; JONES, 1979).

Cada seta da figura indica um dia de administração da pílula anticoncepcional, que inicia no quinto dia do ciclo.

A) Usando a linguagem gráfica usual da matemática, refaça o gráfico. Para isso, determine quais são as variáveis utilizadas e defina cada uma delas. Qual é a unidade de medida usada para cada variável? 


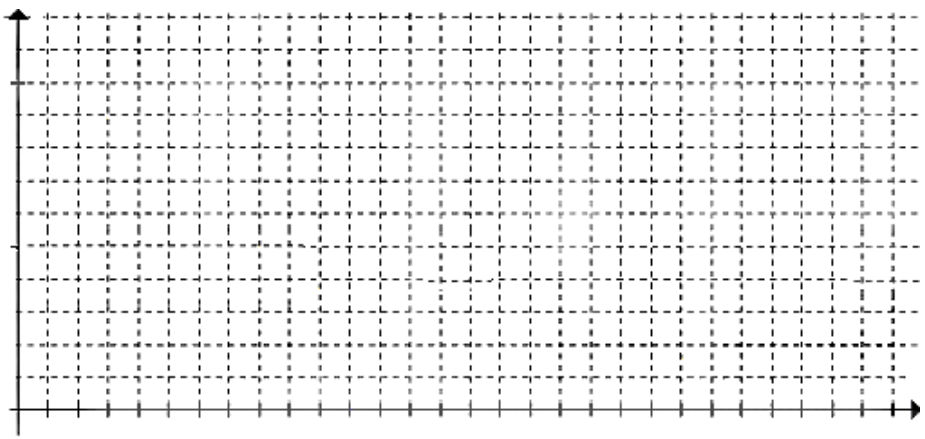

B) No eixo horizontal, o que significa o zero do gráfico? E o 1? E o 2? E o número 28?

Atividade 2: Algumas situações reais admitem representações gráfica e algébrica, - é o que chamamos de modelo matemático. Na seguinte situação, elabore gráfico, tabela e encontre uma expressão algébrica.

Uma pessoa tomou um comprimido de anticoncepcional às 20h. Sabemos que a concentração da droga no sangue decai com o tempo, reduzindo-se à metade a cada 12 horas. Elabore um gráfico para expressar o decaimento dessa concentração, num período de 1 dia. E num período de 3 dias? Encontre uma equação para a variação da concentração da droga, no sangue, em função do tempo.

Vamos, agora, criar um modelo para o fenômeno da absorção de anticoncepcionais de uso diário.

\section{Atividade 3}

A) Uma pessoa tomou um comprimido de anticoncepcional às 20h. A bula do remédio informa que a quantidade de hormônio presente em cada pílula é de 120 microgramas e que essa quantidade decai com o tempo, reduzindo-se à metade a cada 12 horas. Às 20h do dia seguinte, ela toma um novo comprimido. Elabore um gráfico para expressar a variação dessa quantidade, num período de 2 dias.

B) E se a pessoa tomar um comprimido às $20 \mathrm{~h}$, durante 22 dias consecutivos, e só aí parar: a) Elabore um gráfico para expressar a variação dessa concentração, num período de 24 dias. 
b) Elabore uma tabela descrevendo o fenômeno. c) Encontre uma expressão matemática generalizadora.

\section{Referências}

ALMEIDA, T. J. B. Abordagem dos temas transversais nas aulas de ciências do ensino fundamental, no distrito de Arembepe, município de Camaçari-BA. Candombá-Rev. Virtual, v.2, n.1, p. 1-13, 2006.

BARBOSA, J. C. O que pensam os professores sobre a Modelagem Matemática? Zetetikè, Campinas, v.7, n.11, p.67-85, 1999. Disponível em: < http://joneicb.sites.uol.com.br/zetetike.pdf > Acesso em 27 de agosto 2007.

BARBOSA, J. C. O. Modelagem na Educação Matemática: contribuições para o debate teórico. In: REUNIÃO ANUAL DA ANPED, 24, 1-CDROM, Caxambu, Anais... 2001a. Disponível em: < http://joneicb. sites.uol.com.br> Acesso em 20 de agosto 2007.

BARBOSA, J. C. O. Modelagem Matemática e os professores: a questão da formação. Bolema, Rio Claro, ano 14, n.15, p. 5-23, 2001-b. Disponível em: < http://joneicb.sites.uol.com.br/bolema.pdf> Acesso em 27 de agosto 2007.

BARBOSA, J. C. O. Modelagem Matemática e os futuros professores. In: REUNIÂO ANUAL DA ANPED, 25, 2002, Caxambu. Anais...2002. Disponível em: < http://joneicb.sites.uol.com.br/anped2002.pdf > Acesso em 27 de agosto 2007.

BASSANEZI, R. C. Ensino-aprendizagem com modelagem matemática: uma nova estratégia. São Paulo: Contexto, 2004.

BIEMBENGUT, M. S; HEIN, N. Modelagem Matemática no ensino. São Paulo: Contexto, 2003.

BRASIL. Secretaria da Educação Média e Tecnológica. PCNEM: Parâmetros Curriculares Nacionais para o Ensino Médio. Brasília: MEC, 2002a.

BRASIL. Secretaria da Educação Média e Tecnológica. PCN+: Ensino Médio - orientações educacionais complementares aos Parâmetros Curriculares Nacionais. Brasília: MEC, 2002b. 
BRASIL, Secretaria da Educação Média e Tecnológica. PCN: Parâmetros Curriculares Nacionais. Brasília: MEC, 2002-c.

BRASIL, Secretaria da Educação Básica. Orientações Curriculares para o Ensino Médio: Ciências da Natureza, Matemática e suas Tecnologias. Brasília, MEC, 2006.

BRITO, D.; ALMEIDA, L.M. O conceito de função em situações de modelagem matemática. Zetetike, Campinas, v.13, n.23, p. 63-85, 2005.

CALDEIRA, A.; MEYER, J.F. Educação Matemática e Ambiental: uma proposta de formação continuada e de mudanças. Zetetike, Campinas, v.9, n.15/16, p. 155-170, 2001.

CARLSON, M. P.; OEHRTMAN, M.; THOMPSON, P. W. Foundational reasoning abilities that promote coherence in students' understanding of functions. In: M. P. Carlson; C. Rasmussen (Eds.). Making the connection: Research and teaching in undergraduate mathematics (p. 150-171, 2007). Washington, DC: Mathematical Association of America. Disponível em: < http://pat-thompson.net/PDFversions/2006MAA\%20Functions.pdf > Acesso em 20 de outubro 2007.

DEMANA, F, LEITZEL, J. Estabelecendo conceitos fundamentais através da resolução de problemas numéricos. In: Coxord, A. F., Shulte, A. P. As idéias da álgebra. São Paulo: Atual, 1995.

FIGUEIRÓ, M. N. D. A viabilidade dos Temas Transversais à luz da questão do trabalho docente. Revista de Psicologia Social e Institucional, Londrina, v.2, n.1, jun. 2000. Disponível em: < http://www2.uel.br/ccb/ psicologia/revista/textov2n12.htm > Acesso em 20 de outubro 2007.

LIMA, E. L. Conceitualização, Manipulação e Aplicações: os três componentes do ensino da Matemática. Revista do Professor de Matemática RPM, Rio de Janeiro, n.41, p. 1-6, 1999.

LIMA, E. L. A propósito de contextualização. Revista do Professor de Matemática - RPM, Rio de Janeiro, n.58, p. 28-32, 2005.

MENNA BARRETO, Marina. Matemática e Educação Sexual: modelagem do fenômeno da absorção/eliminação de anticoncepcionais orais diários. Dissertação de Mestrado. PPG-Ensino de Matemática, UFRGS, Porto Alegre. 2008. Disponível em: < http://euler.mat.ufrgs.br/ vclotilde/ 
orientacoes/dissert_marinambarreto_2008_inteiro.pdf $>$ Vídeo disponível na Biblioteca digital UFRGS < http://sabix.ufrgs.br/ALEPH/CLUT47 LEEE4L625EU1IKLM7FSLSEXDUSSE2Q1PFPRE7DI4FR2R34259/file/start-0>

MICOTTI, M. C. O. O ensino e as propostas pedagógicas. In: BICUDO, M. A. V. (Org.) Pesquisa em educação matemática: concepções e perspectivas, UNESP, São Paulo, 1999.

MORAES, M. S. S. et al. Formação de Valores no Processo de Ensino de Aprendizagem de Matemática do Ensino Médio: A Pluralidade Cultural e a Orientação Sexual. In: PINHO, S. Z; SAGLIETTI, J. R. C. (Org.). Núcleos de Ensino Universidade Estadual Paulista (Livro Eletrônico Institucional), São Paulo:UNESP, 2007. Disponível em: <http://www.unesp.br/ prograd/PDFNE2005/artigos/capitulo\%205/formacaodevalores.pdf> Acesso em 25 de outubro 2007.

MUÑOZ, M. O Uso de Um Agente Cognitivo Piagetiano na Resolução do Problema de Planejamento de Trajetória. Disponível em: < http://www. inf. ufrgs.br/pos/SemanaAcademica/Semana98/munoz.html> Acesso em 5 de outubro 2007.

PONTE, J.P. A Modelação no processo de aprendizagem. Educação e Matemática, APM, Portugal, n.23, p. 15-19, 1992. Disponível em: <http:/ /www.educ.fc.ul.pt/docentes/jponte/docs-pt/92-Ponte(Educ\&Mat).doc> Acesso em 20 de outubro 2007.

SCHOEN, H. L. Ensinar álgebra elementar focalizando problemas. In: CoxFord, A. F., Shulte, A. P. As idéias da álgebra. São Paulo: Atual, 1995.

STEFFE, 1.P.; THOMPSON, P.W. Teaching experiment methodology: underlying principles and essential elements. In: LESCH, R.; KELLY, A.E. (Ed.) Research design in mathematics and Science Education. Hilldale: Erlbaum, 2000. Disponível em: < http://pat-thompson.net/PDFversions/ 2000TchExp.pdf.> Acesso em 20 de outubro 2007.

TELÖKEN, M. A.; DEL PINO, J. C. Refletindo sobre a prática pedagógica, In: VI Encontro sobre investigação na escola, 2006, Rio Grande. Anais... Rio Grande, 2006.

TALL, D. BAKAR, N. Students' Mental Prototypes for Functions and Graphs, Int.J. Math Ed Sci \& Techn., n. 23, p. 39- 50, 1992. Disponível em: <http://www.davidtall.com/> Acesso em 01 de fevereiro 2008. 
THOMAS, J. A.; JONES E. J. Anticoncepcionais Orais. In: BEVAN, J. A. Fundamentos de Farmacologia: introdução aos princípios de ação de drogas. São Paulo: Harper \& Row do Brasil, 1979.

TONATTO, S.; SAPIRO, C. M. Os novos parâmetros curriculares das escolas brasileiras e educação sexual: uma proposta de intervenção em ciências. Psicologia Social, v.14, n.2, p. 163-175, 2002.

TORRES, C. Os Temas Transversais estão na mira do cotidiano escolar. Entrevista com Prof. Ulisses Ferreira de Araújo. Revista Simpro, Cultura, Sd. Disponível em: < http://www.abrae.com.br/entrevistas/entr_uli.htm $>$ Acesso em 20 de outubro 2007.

XAVIER, C. M. S. Da álgebra à enfermagem: um caminho de mão dupla. Dissertação de Mestrado. PPG- Ensino de Matemática, PUC-SP, 2006. 